\title{
Immunisation with proteins expressed during chronic murine melioidosis provides enhanced protection against disease
}

\author{
Olivia L. Champion ${ }^{\mathrm{a}}$, Louise J. Gourlay ${ }^{\mathrm{b}}$, Andrew E. Scott ${ }^{\mathrm{c}}$, Patricia Lassaux ${ }^{\mathrm{b}}$, \\ Laura Conejero $^{\mathrm{d}}$, Lucia Perletti ${ }^{\mathrm{b}}$, Claudia Hemsley ${ }^{\mathrm{a}}$, Joann Prior ${ }^{\mathrm{a}, \mathrm{c}}$, Gregory Bancroft ${ }^{\mathrm{d}}$, \\ Martino Bolognesi ${ }^{\mathrm{b}, \mathrm{e}}$, Richard W. Titball ${ }^{\mathrm{a}, *}$ \\ a College of Life and Environmental Sciences, University of Exeter, Exeter, UK \\ b Department of Biosciences, University of Milan, Milan 20133, Italy

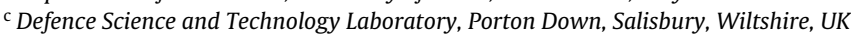 \\ ${ }^{\mathrm{d}}$ London School of Hygiene and Tropical Medicine, Keppler Street, London WC1E 7HT, UK \\ e Consiglio Nazionale delle Ricerche, Institute of Biophysics, University of Milan, Milan 20133, Italy
}

\section{A R T I C L E I N F O}

\section{Article history:}

Received 7 December 2015

Received in revised form 29 January 2016

Accepted 15 February 2016

Available online 23 February 2016

\section{Keywords:}

Burkholderia pseudomallei

Melioidosis

Vaccine

Chronic

\begin{abstract}
A B S T R A C T
There is an urgent need for an effective vaccine against human disease caused by Burkholderia pseudoma$l l e i$, and although a wide range of candidates have been tested in mice none provide high level protection. We considered this might reflect the inability of these vaccine candidates to protect against chronic disease. Using Q-RT PCR we have identified 6 genes which are expressed in bacteria colonising spleens and lungs of chronically infected mice. Three of the genes (BPSL1897, BPSL3369 and BPSL2287) have been expressed in Escherichia coli and the encoded proteins purified. We have also included BPSL2765, a protein known to induce immune responses associated with a reduced incidence of chronic/recurrent disease in humans. Immunisation of mice with a combination of these antigens resulted in the induction of antibody responses against all of the proteins. Compared with mice immunised with capsular polysaccharide or LolC protein, mice immunised with the combination of chronic stage antigens showed enhanced protection against experimental disease in mice.
\end{abstract}

(c) 2016 Elsevier Ltd. All rights reserved.

\section{Introduction}

Burkholderia pseudomallei is the etiological agent of melioidosis, a serious and often fatal disease of humans and a wide variety of animals [1]. The disease is an important medical problem in many tropical regions of the world. For example, in North-East Thailand, melioidosis is the third most common cause of death from infectious diseases, exceeded only by HIV and tuberculosis [2]. In Darwin, Northern Australia, melioidosis is the most common cause of fatal community-acquired septicemic pneumonia [3]. Melioidosis is difficult to treat as $B$. pseudomallei is resistant to many antibiotics [4]. The bacterium is susceptible to some newer $\beta$-lactam antibiotics including ceftazidime $[5,6]$ but a protracted course of treatment (typically 20 weeks) is routinely required [7]. Chronic disease is common and disease relapse has been reported $[8,9]$.

\footnotetext{
* Corresponding author. Tel.: +44 1392 725157; fax: +44 1392723434.

E-mail address: r.w.titball@exeter.ac.uk (R.W. Titball).
}

Against this background, there may be an opportunity to use vaccines for the control of naturally occurring disease. Recent work has shown that a vaccine would be a cost-effective intervention in Thailand if used in high-risk populations such as diabetics [10]. However, at present there is no available human vaccine, though a wide range of candidates including live attenuated mutants, killed cells, protein or polysaccharide sub-units and naked DNA vaccines have been tested in mice (for recent reviews see [11-13]). All of these vaccines are able to induce some protective immunity, protecting against the acute form of the disease. However, all of the candidates fail to provide long-term control of disease of which persistent, chronic melioidosis is a feature.

B. pseudomallei differs from many other pathogens, yet is similar to Mycobacterium tuberculosis, in its capacity for intracellular survival for many years. Chronic melioidosis is often misdiagnosed as tuberculosis and the two diseases have common histological features such as the presence of multinucleated giant cells and granulomas, suggesting that melioidosis and tuberculosis have shared immunological mechanisms. Like melioidosis, it is difficult to devise vaccines that provide sterile immunity against tuberculosis. However, one promising approach is to devise tuberculosis 
sub-unit vaccines which include antigens expressed during the chronic or latent phase of disease [14-16]. These vaccines have been shown to be effective in animal models of disease and are currently in human clinical trials [17].

Recently, the $B$. pseudomallei transcriptional response to a range of in vitro conditions reflecting the diversity of niches occupied by the bacterium was reported [18]. Evaluation of the transcriptional response of $B$. pseudomallei in conditions mimicking the environment inside the granuloma, including hypoxia and nutrient starvation, has provided clues to the repertoire of antigens expressed by the pathogen as it adapts to long-term persistence in the host. Our hypothesis is that it is possible to prime the host immune system to target $B$. pseudomallei during the chronic stage of melioidosis by selecting vaccine antigens expressed by the bacterium in the chronic phase of infection. In this study we have identified, constructed and evaluated chronic stage vaccine candidates in the murine model of infection. Our results indicate that, in a murine model of disease, the degree of protection afforded by immunisation with chronic stage vaccine antigens is greater than the protection afforded by two of the leading sub-unit candidates (CPS and LolC).

\section{Materials and methods}

\subsection{Bacterial strains}

B. pseudomallei strains 576 and $\mathrm{K} 96243$ were used in this study. Both are clinical isolates of $B$. pseudomallei from cases of melioidosis in Thailand [19]. The intraperitoneal (i.p.) median lethal doses of these strains are reported to be 80 and 262 colony forming units (CFU), respectively [19]. Bacteria were cultured in Luria-Bertani (LB) medium at $37^{\circ} \mathrm{C}$.

\subsection{Identification of chronic stage antigens}

B. pseudomallei transcriptional profiles from in vitro conditions thought to reflect the environment inside a granuloma were obtained [18]. Transcriptome data was referenced to the transcriptome profile of $B$. pseudomallei grown in LB broth at $37^{\circ} \mathrm{C}$. Transcriptional responses from $B$. pseudomallei grown in low $\mathrm{pH}$, peroxide, low oxygen and low nutrient (water) were interfaced and evaluated, and genes that were upregulated in at least three of the four granuloma mimicking conditions were selected. The annotation and cellular location of the protein products of selected genes using PSORTb [20] were evaluated.

\subsection{Chronically infected mouse tissues}

Chronic infection studies were performed in accordance with the guidelines of the Animals (Scientific Procedures) Act of 1986 and were approved by the local ethical review committee at the London School of Hygiene and Tropical Medicine. Female C57BL/6 mice (6-8 week-old; Harlan Laboratories, Bicester, Oxon, UK) were used throughout the chronic infection studies. For each infection, aliquots were thawed from frozen bacteria stocks and diluted in pyrogen-free saline (PFS). Prior to intranasal (i.n.) infection, mice were anaesthetised intraperitoneally (i.p.) with ketamine (50 mg/kg; Ketaset; Fort Dodge Animal, Iowa, USA) and xylazine (10 mg/kg; Rompum; Bayer, Leverkusen, Germany) diluted in PFS. Infection was performed by administering a total volume of $50 \mu \mathrm{l}$ i.n. containing $100 \mathrm{CFU}$ of $B$. pseudomallei strain 576. Infection dose was confirmed as described elsewhere [21]. Control uninfected mice received $50 \mu \mathrm{l}$ i.n. of PFS. At day 65, 95 and 102 p.i. mice were killed and lungs and spleens aseptically removed into $3 \mathrm{ml}$ of cold Trizol ${ }^{\circledR}$ Reagent (Invitrogen, CA, USA). Organs were homogenised using a Polytron homogenizer and samples were stored at $-80^{\circ} \mathrm{C}$ until further processing.

\subsection{Isolation of mRNA from infected mouse tissue}

Total RNA was extracted from the infected lung and spleen homogenates in Trizol ${ }^{\circledR}$ Reagent described above according to the manufacturer's recommendations. In brief, cell debris was removed by centrifugation at $12,000 \times g$ for $10 \mathrm{~min}$. Supernatants $(1 \mathrm{ml}$ each) were transferred to fresh tubes and $0.2 \mathrm{ml}$ chloroform was added to initiate phase separation. The samples were centrifuged for 15 min at $12,000 \times \mathrm{g}$ at $4{ }^{\circ} \mathrm{C}$, and the aqueous phase was transferred to fresh tubes. Total RNA was precipitated by adding $0.5 \mathrm{ml}$ isopropanol and incubating the samples over-night at $-20^{\circ} \mathrm{C}$. The RNA was pelleted by centrifugation for $45 \mathrm{~min}$ at $13,000 \mathrm{rpm}$ at $4{ }^{\circ} \mathrm{C}$; the supernatant was discarded, and the pellet washed with $75 \%$ ethanol in DEPC-water. The RNA pellet was air dried for $5 \mathrm{~min}$ at room temperature and re-suspended in $50 \mu$ l nucleasefree water. Contaminating DNA was removed by on-column DNase I digest and RNA cleanup using the RNeasy kit (Qiagen) according to the manufacturer's recommendations. In brief, $350 \mu \mathrm{l} \mathrm{RLT}$ buffer supplemented with $10 \mu \mathrm{l} / \mathrm{ml}$ ß-mercaptoethanol and $250 \mu \mathrm{l}$ absolute ethanol was added to each RNA sample, before loading onto RNeasy spin columns. After brief centrifugation, $350 \mu \mathrm{l}$ RW1 buffer was added and columns re-centrifuged. $10 \mu \mathrm{l}$ DNase I stock solution ( 27 Kunitz units) mixed with $70 \mu$ l Buffer RDD (both component of the RNase-free DNase kit, Qiagen) were added to the columns, which were incubated at room temperature for $30 \mathrm{~min}$. The columns were washed once with $350 \mu \mathrm{l}$ RW1 buffer and twice with $500 \mu l$ RPE buffer. Total RNA was eluted in $2 \times 40 \mu$ l nucleasefree and checked for DNA contamination by PCR. RNA from 6 mice in each experimental group was pooled before reverse transcription PCR analysis.

\subsection{Quantitative reverse transcription $P C R$}

Reverse transcription (RT) and PCR were performed in a single reaction using Quantitect SYBR Green RT PCR kit (Qiagen) according to the manufacturers' instructions. For template, total RNA from the lungs and spleens of six chronically infected mice collected at 65 days, 95 days and 102 days post infection was pooled into separate lung and spleen template samples. Three PCRs were carried out for each chronic gene of interest using total RNA isolated from lungs and, separately, spleen (Table 1). One control was performed for each chronic gene of interest using total RNA isolated from bacteria in lungs and spleen as template but without the RT step. $B$. pseudomallei housekeeping genes BPSL2188 (aceA) and BPSL3159 ( $g l t B$ ) were used as internal controls for expression profiling. Both BPSL2188 and BPSL3159 were selected as controls as neither of the genes was found to be differentially regulated in vivo in mice compared to broth culture (data not presented). In a reaction volume of $50 \mu \mathrm{l}, 25 \mu \mathrm{l}$ of $2 \times$ QuantiTect SYBR Green RT-PCR master mix, $0.5 \mu \mathrm{M}$ of forward and reverse primers, $0.5 \mu$ l QuantiTect RT mix, $<500 \mathrm{ng}$ template RNA, RNase-free water was added to make the reaction volume to $50 \mu \mathrm{l}$. PCR reaction conditions were; $50^{\circ} \mathrm{C}$ for 30 min for reverse transcription, followed by a PCR initial activation step of $95^{\circ} \mathrm{C}$ for $15 \mathrm{~min}$. Four step cycling of $94^{\circ} \mathrm{C}$ for $15 \mathrm{~s}$ (denaturation), $50^{\circ} \mathrm{C}$ for $30 \mathrm{~s}$ (annealing), $72^{\circ} \mathrm{C}$ for $30 \mathrm{~s}$ (extension) and $40^{\circ} \mathrm{C}$ for $15 \mathrm{~s}$ (40 cycles). Reactions were performed using a Stratagene Mx3005P Q-PCR system. Ct values were calculated for all samples. Relative expression levels were calculated using $2^{-\Delta \Delta c t}$ analysis.

\subsection{Antigen production}

Genes encoding for BPSL1897 (residues 40 to 155), BPSL3369 (residues 1 to 506) and BPSL2287 (residues 1 to 107) were 
Table 1

Primers used for Q-RT PCR analysis of gene expression.

\begin{tabular}{ll}
\hline Primer name & Primer sequence \\
\hline BPSL3312 F & GAATATCTCGCGTTTCTCGG \\
BPSL3312 R & TCTGTGCTTCGTTGATCTCG \\
BPSL2289 F & CAATTTTGTCGAAGGCGAAT \\
BPSL2289 R & TAGTCGACTTCCTGCTCCGT \\
BPSL1897 F & TCGACGAACTACACGTGCTC \\
BPSL1897 R & ATGATGTTGGTCGGGTTGAT \\
BPSL2287F & AAAGCCTTGCGTACATCGAC \\
BPSL2287R & GTCCTTCACGTTCGGATTGT \\
BPSL3369F & ATCTGAACATCGAATTCCCG \\
BPSL3369R & ACGTTGTCGAAATACTCGCC \\
BPSL3247F & AACGCCCTCGTCTATCACAC \\
BPSL3247R & TGCTGTTGAAGTAGCCGTTG \\
BPSL0296F & TACGGTAGGTGAAATTGCGG \\
BPSL0296R & CGTCGTCCTTCTTTTTCTCG \\
BPSL1899F & GATGCATCGCTTCTTCAAGG \\
BPSL1899R & ATAAGACCGGCGATCAACC \\
BPSS0369F & ATCGTCTGCGTGTGCAAGT \\
BPSS0369R & AACTGGAGTTCTTCGAACGTG \\
BPS gltB F & CGCACCATGACATCTATTCG \\
BPS gltB R & ACCGGATTGACGTTCTTCAG \\
BPS aCeA F & CTCTGGACGCTCATCAACAA \\
BPS aCeA R & CCGATACAGCTGAAGAAGCG \\
\hline
\end{tabular}

purchased as codon-optimised synthetic genes (GenScript). To facilitate subsequent cloning by digestion and ligation into pGEX4T-1 (Life Technologies), BamH1 and EcoR1 restriction sites were added at the $5^{\prime}$ and $3^{\prime}$ ends of the genes, respectively. BPSL1897, BPSL3369 and BPSL2287 were expressed as N-terminal glutathione-S-transferase (GST) fusion proteins in BL21 Star ${ }^{\mathrm{TM}}$ (DE3) cells (Life Technologies) in Luria Bertani Broth (BPSL3369 and BPSL2287) or Terrific Broth (BPSL1897), inducing with $0.5 \mathrm{mM}$ isopropyl $\beta$-D-1-thiogalactopyranoside (IPTG) at $20^{\circ} \mathrm{C}$ overnight.

Bacterial cells from a 0.51 culture were harvested and lysed in PBS using a cell disruption system at $25 \mathrm{mPa}$ (Constant Systems Limited). Following centrifugation at $18,000 \mathrm{rpm}$ and addition of $50 \mu \mathrm{g} / \mu \mathrm{l}$ deoxyribonucleases (Sigma-Aldrich) and $10 \mathrm{mM}$ magnesium chloride, the soluble fraction was loaded onto a $5 \mathrm{ml} \mathrm{GSTrap}$ FF column (BPSL2287) or $5 \mathrm{ml}$ Glutathione Sepharose 4B resin (GE healthcare) in a gravity-flow setup (BPSL3369), pre-equilibrated with PBS containing 10\% glycerol and $5 \mathrm{mM}$ dithiothreitol (DTT). A final wash was carried out with PBS to remove DTT and glycerol prior to cleavage with 20U (BPSL3369) or 40U (BPSL2287) thrombin (Sigma-Aldrich). Tag cleavage was carried out in PBS, incubating overnight at $20^{\circ} \mathrm{C}$ (with gentle rotation for batch purifications). Thrombin was removed from the cleaved protein solutions using a $1 \mathrm{ml}$ HiTrap Benzamidine FF column (GE Healthcare), preequilibrated in PBS containing $1 \mathrm{M} \mathrm{NaCl}$. Proteins were exchanged into PBS using a PD10 desalting column (GE Healthcare) and concentrated to $1 \mathrm{mg} / \mathrm{ml}$ using Amicon Ultra-15 Centrifugal Filter Units (Millipore) with an appropriate MW cut-off. Recombinant BPSL2765 was produced as a N-terminal histidine-tagged protein as previously described [31]. Residues 47 to 243 of BPSL2277 (LolC$\mathrm{N})$ were cloned into pET28a and expressed with an N-terminal histidine tag in Rosetta (DE3) pLysS cells in LB, inducing with $0.5 \mathrm{mM}$ IPTG at $20^{\circ} \mathrm{C}$ overnight. Bacterial cells from a 0.51 culture were harvested and mechanically lysed in PBS, and fractionated as described above. Following DNAse treatment, the supernatant was loaded onto a $5 \mathrm{ml}$ Bio-Scale Mini Profinia IMAC cartridge (Bio-rad) and exchanged into PBS using a $50 \mathrm{ml}$ Mini-Scale BioGel P6 Desalting cartridge using the Profinia Protein Purification System, according to standard Bio-rad protocols. The protein was purified on a HiLoad Superdex 75 (16/60) gel filtration column, pre-equilibrated in PBS (flow rate of $1 \mathrm{ml} / \mathrm{min}$ ), using an AKTA Protein Purification System (GE Healthcare). Proteins were analysed by SDS-PAGE on a $12 \%$ Bis-Tris NuPAGE pre-cast gel (Life technologies) in NuPAGE MES running buffer, or a $12 \%$ Bolt Bis-Tris Plus pre-cast gel (Life technologies) in Bolt MOPS running buffer (BPSL1897).

Manno-heptopyranose capsular polysaccharide (CPS) was prepared from an $\mathrm{O}$-antigen deficient mutant strain $B$. thailandensis E555::wbil (pKnock-KmR). This strain was generated through disruption of the O-antigen synthesis cluster in B. thailandensis E555 [22] by insertional inactivation of the wbil gene (gene $\mathrm{BTH}_{-} \mathrm{I}_{1483}$ in B. thailandensis E264) using the pKnock-Km suicide vector [23]. Briefly, an internal fragment from the wbil gene in $B$. thailandensis E555 was amplified by PCR using primers 306 (5'- CTGCAGTCTATCGGGCGACGAAGGAG-3') and 307 (5'CTGCAGGCCTTGTCGGTCGAGATCAG-3'), inserted into pCR $^{\circledR}$-blunt II-TOPO ${ }^{\circledR}$ and cloned into Escherichia coli TOP10 cells. Following sequence verification, the insert was released by digestion with $K p n I$ and $\mathrm{XbaI}$ and purified by gel extraction using a MinElute Gel Extraction kit (Qiagen). This was ligated into similarly prepared pKnock-Km vector and cloned into $E$. coli S17-1 $\lambda$-pir. The resulting pKnock-Km-wbil vector was transferred into B. thailandensis E555 by conjugation and recombinants were selected by supplementing growth media with kanamycin and gentamicin. Insertion into wbil was confirmed by Southern hybridisation and loss of O-antigen synthesis was confirmed by Western hybridisation following SDS PAGE using the O-antigen specific monoclonal CC6 [24]. Continued synthesis of the manno-heptose capsule was confirmed by Western hybridisation using the capsule-specific monoclonal $4 \mathrm{VIH} 12$ [25]. Capsular polysaccharide was isolated from this strain using a modified hot aqueous-phenol procedure of Burtnick et al. [26].

\subsection{Protection study}

Protection studies were carried out according to the requirements of the UK Animal (Scientific Procedures) Act 1986 under project licence PPL 30/2623. This project licence was approved following an ethical review by Dstl's Animal Welfare and Ethical Review Body. Protection studies were performed using female BALB/c mice (BALB/c; Charles River UK) implanted with a subcutaneous Pico transponder (Uno BV, Netherlands). Mice were 6-8 weeks of age and weighed 16-20 grams on arrival. Mice were randomly allocated into cages of five with environmental enrichment. Mice were under a $12 \mathrm{~h} \mathrm{light/dark}$ cycle (at 19 to $23^{\circ} \mathrm{C}$ and 45 to $65 \%$ relative humidity. There was free access to food (Labdiet certified rodent diet 5002 and Labdiet EUrodent 22\% diet 5LF5; International Product Supplies) and water throughout the study. Mice were housed in a conventional animal unit during immunisations in rooms supplied with rough filtered air giving 20 to 25 air changes per hour. Mice were checked at least twice daily following challenge and clinical signs for each mouse were scored. Throughout this study humane end-points were used to minimise suffering, with culls performed via cervical dislocation at the end-point.

Mice ( $n=10$ per immunogen) were immunised via the i.p. route with immunogen formulated in SAS adjuvant (monophosphoryl lipid A from Salmonella minnesota ( $25 \mu \mathrm{g}$ per mouse per dose) and synthetic trehalose dicorynomycolate $(25 \mu \mathrm{g}$ per mouse per dose) as an oil-in-water emulsion of $2 \%$ squalene and $0.2 \%$ Tween ${ }^{\circledR}$ 80; Sigma). Chronic proteins were delivered as a pool (BPSL2765, BPSL3369, BPSL2287 and BPSL1897, $5 \mu \mathrm{g}$ of each protein per mouse per dose). Purified CPS (10 $\mu$ g per mouse per dose) was delivered in combination with the chronic antigens where appropriate. Immunisations were performed on days 0,14 and 28 and mice were challenged five weeks after the final immunisation with $7.46 \times 10^{4}$ CFU of B. pseudomallei $\mathrm{K} 96243\left(100 \times \mathrm{LD}_{50}\right)$ via the i.p. route.

\subsection{IgG1 and IgG2A ELISA}

Serum was recovered from the tail vein of each mouse two weeks after the final immunisation and pooled by cage (to give 
$n=2$ per vaccine). Antibody responses directed against the various protein antigens were assessed by ELISA essentially as previously described [27] using $5 \mu \mathrm{g} / \mathrm{ml}$ of each protein to coat ELISA wells. A reading of twice background or above was considered positive and the titre was determined to be the reciprocal of the final positive dilution.

\section{Statistical analysis}

Survival data was analysed in the program GraphPad PRISM v6.0 using a log rank (Mantel-Cox) test. Significance was assessed at the 95\% confidence level.

\section{Results}

\subsection{Identification of chronic stage antigens}

We first compared the gene expression profile of $B$. pseudomallei grown in granuloma mimicking conditions. Nine putative chronic infection stage B. pseudomallei genes that were upregulated in at least three of four in vitro conditions; low oxygen, nutrient deprivation, low pH and peroxide were identified: BPSL0296, BPSL2287, BPSL2289, BPSL3312, BPSS0369, BPSL1899, BPSL3369, BPSL3247 and BPSL1897. The nine genes represented different classes of genes, including hypothetical proteins with membrane or extracellular locations (Table 2).

\subsection{Quantitative reverse transcriptase PCR using total RNA lungs and spleens of chronically infected mice}

We next tested whether any of the putative chronic infection stage $B$. pseudomallei genes were expressed during chronic disease. Total RNA from individual mice which had been challenged with bacteria and developed chronic disease [28] was reverse transcribed and amplified and gene-specific mRNA quantified using real time PCR. The use of multiple internal controls, aceA and gltB, allowed quantification of transcripts from each of the putative chronic stage genes in pooled lung and spleen samples from mice. B. pseudomallei putative chronic genes BPSL1897, BPSL3369, BPSL0296, BPSL3247, BPSL2287 and BPSL1899 were transcribed at higher levels than one or both housekeeping genes aceA and gltB in both lungs and spleens of chronically infected mice (Table 3 ). B. pseudomallei genes BPSL3312, BPSL2289 and BPSS0369 were transcribed at a lower level than housekeeping genes in lungs and spleens of chronically infected mice. Therefore, of the nine genes identified from in vitro transcriptome analysis, six, BPSL0296, BPSL1897, BPSL1899, BPSL2287, BPSL3247 and BPSL3369, were found to be expressed at levels higher than housekeeping genes by

Table 2

Genes encoding putative chronic stage antigens in B. pseudomallei.

\begin{tabular}{|c|c|c|}
\hline Target & Predicted function & $\begin{array}{l}\text { Predicted cellular } \\
\text { localisation }^{\mathrm{a}}\end{array}$ \\
\hline BPSL0296 & Hypothetical protein & Unknown \\
\hline BPSS0369 & $\begin{array}{l}\text { Putative bacterioferritin } \\
\text { ferredoxin protein }\end{array}$ & Unknown \\
\hline BPSL1897 & $\begin{array}{l}\text { Hypothetical contains a Tad-E } \\
\text { domain }\end{array}$ & $\begin{array}{l}\text { Cytoplasmic } \\
\text { membrane }\end{array}$ \\
\hline BPSL1899 & $\begin{array}{l}\text { Putative fimbrial assembly like } \\
\text { protein }\end{array}$ & Unknown \\
\hline BPSL2287 & Iron cluster assembly protein & Cytoplasmic \\
\hline BPSL2289 & Cysteine desulfurase & Cytoplasmic \\
\hline BPSL3247 & Lipoprotein & $\begin{array}{l}\text { Multiple predicted } \\
\text { localisations }\end{array}$ \\
\hline BPSL3312 & Putative glycosyltransferase & Cytoplasmic \\
\hline BPSL3369 & Acetaldehyde dehydrogenase & Cytoplasmic \\
\hline
\end{tabular}

a Predicted using PSORTb version 3.0.2
Table 3

Relative (compared to aceA or gltB) levels of expression of genes encoding putative chronic stage antigens in $B$. pseudomallei pooled mRNA isolated from the lung or spleens of 6 chronically infected mice.

\begin{tabular}{lllll}
\hline Target & Lung $($ ace $A)$ & Lung $(g l t B)$ & Spleen $($ ace $A)$ & Spleen $(g l t B)$ \\
\hline BPSL0296 & 2.5 & 0.3 & 10.6 & 13.6 \\
BPSS0369 & $2.1 \mathrm{e}-3$ & $2.5 \mathrm{e}-4$ & 0.75 & 0.96 \\
BPSL1897 & 17.1 & 2.1 & 1.17 & 1.5 \\
BPSL1899 & 5 & 0.44 & 1.4 & 1.8 \\
BPSL2287 & 2.6 & 0.3 & 2.78 & 3.58 \\
BPSL2289 & 0.29 & 0.036 & 0.01 & 0.016 \\
BPSL3247 & 2.6 & 0.3 & 6.6 & 8.5 \\
BPSL3312 & 4.16 & 0.5 & 0.08 & 0.11 \\
BPSL3369 & 12.1 & 1.5 & 4.4 & 5.65 \\
\hline
\end{tabular}

B. pseudomallei during chronic infection. These genes were therefore selected for over-expression of the encoded proteins.

\subsection{Over-expression and purification of proteins}

Of the 6 genes we identified that were highly expressed during chronic infection, we were able to overexpress and purify three of the encoded proteins (BPSL1897, BPSL2287 and BPSL3369). Two of the proteins (BPSL0296 and BPSL3247) were insoluble when expressed in E. coli and we could not detect expression of BPSL1899. Tested BPSL1897, BPSL2287 and BPSL3369 were expressed as Nterminal GST-tagged fusion proteins, and purified as described in Section 2. Yields ranged from 2 to $5 \mathrm{mg}$ per litre of bacterial culture (Table 4). Following removal of the GST-tag, BPSL3369 migrated with a MW in line with the theoretical value of $55.6 \mathrm{kDa}$ (Fig. 1). There were diverse bands visible for BPSL2287 at approx. $12 \mathrm{kDa}, 14 \mathrm{kDa}, 26 \mathrm{kDa}, 28 \mathrm{kDa}$, and a faint band at $40 \mathrm{kDa}$ (Fig. 1). As BPSL2287 contains three cysteine residues in the conserved $\mathrm{CX}_{\mathrm{n}}$ CGCG motif shared by HesB family members it is likely that the $12 \mathrm{kDa}$ and $14 \mathrm{kDa}$ bands correspond to diversely compacted forms of the protein monomer, whereas the $26 \mathrm{kDa}$ and $28 \mathrm{kDa}$ bands are likely to represent variably reduced dimeric forms of the protein. The highest band ( $40 \mathrm{kDa}$ ) is a likely tetrameric form. Such observations are in agreement with its structural homolog (71\% sequence identity), an iron-sulfur [2Fe-2S] cluster assembly protein (IscA) from E. coli (PDB entry 1S98) that exists in both dimeric and tetrameric forms in solution [29]. As it was not possible to remove the GST tag (25 kDa) from BPSL1897 (11.9 kDa), the tagged form of the protein produced a band at approx. $35 \mathrm{kDa}$.

We also selected BPSL2765 for testing as a chronic stage antigen. Suwannasaen et al. [30] previously showed that antibodies against BPSL2765 were found at 10-fold-higher levels in patients who had only one episode of melioidosis, in comparison with patients who had suffered recurrent episodes. This finding suggests that responses against BPSL2765 provide protection against chronic/recurrent disease. BPSL2765 was produced as a histidinetagged protein as previously reported [31] with a yield of $23 \mathrm{mg} / \mathrm{l}$ culture and was judged to be $>95 \%$ pure (Table 2 ). LolC was purified (approx. $20 \mathrm{mg}$ protein/l culture; $>90 \%$ pure) as a C-terminal Histag, as described in Section 2, and migrated with a $M W$ of $26 \mathrm{kDa}$, in agreement with its theoretical $M W$ of $26.4 \mathrm{kDa}$ (Fig. 1). Protein

Table 4

Chronic stage vaccine antigens purified for this study.

\begin{tabular}{llcl}
\hline Protein & Vector & Yield (mg/L culture) & Estimated purity (\%) \\
\hline BPSL1897 & pGEX4T-1 & 5 & $>90$ \\
BPSL2287 & pGEX4T-1 & 4 & $>90$ \\
BPSL2765 & pET14-b & 23 & $>95$ \\
LolC-N & pET28a & 20 & $>90$ \\
BPSL3369 & pGEX4T-1 & 2 & $>85$ \\
\hline
\end{tabular}




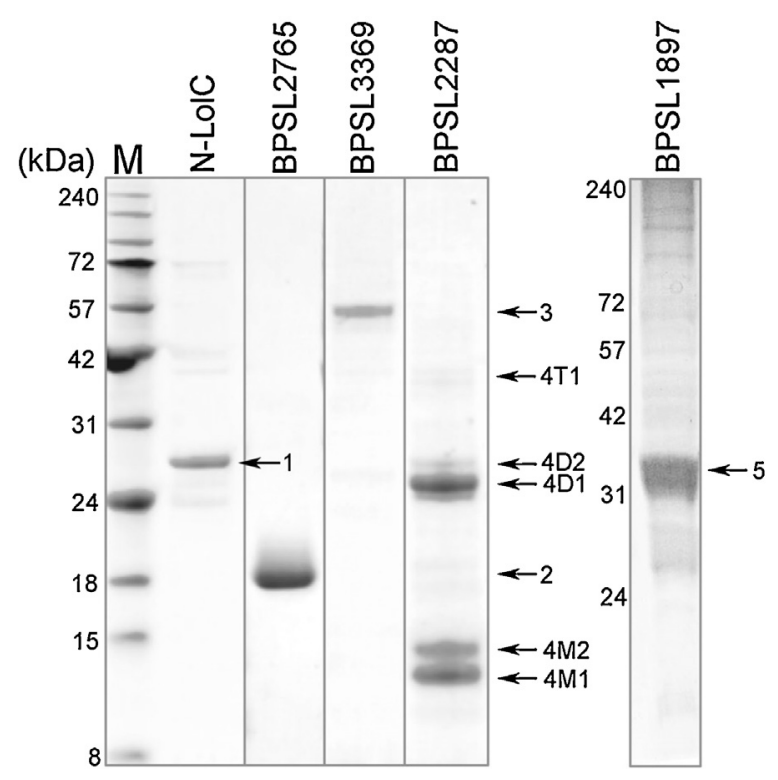

Fig. 1. SDS-PAGE analysis of purified chronic antigens. Plasmids carrying chronic antigen genes were transformed into BL21 (DE3) Star cells or Rosetta (DE3) pLysS cells (N-LolC) and protein expression was carried out, as described in Section 2. Purified bands of N-LolC, BPSL2765 and BPSL3369 are indicated by arrows 1 to 3, respectively. The diverse oligomeric forms of BPSL2287 are indicated by arrows 4 (4M1 and 4M2 = monomeric forms 1 and 2; 4D1 and 4D2 = dimeric forms 1 and 2, and $4 \mathrm{~T} 1$ = tetrameric form), and the band corresponding to GST-BPSL1897 is indicated by arrow 5. Molecular weight markers (Genespin S.r.l.) are indicated on the left in both panels in $\mathrm{kDa}$.

purity for all antigens was judged by SDS-PAGE and ranged from 90 to $95 \%$ (Table 4 ).

\subsection{ELISA}

Mice were immunised with a combination of BPSL2765, BPSL3369, BPSL2287 and BPSL1897 as described above. The immunised mice were tail-bled two weeks after the final boost and levels of serum antibodies were assessed using an ELISA (Table 5). The polarisation of the immune response was assessed through analysis of levels of antigen-specific IgG1 and IgG2a; the relative proportions of these sub-classes reflect the bias of an immune response in the mouse. All of the mice immunised with adjuvant only failed to produce detectable IgG1 or IgG2a to the chronic stage antigens. In mice receiving the vaccines containing chronic stage proteins, strong levels of both IgG1 and IgG2a were produced to proteins BPSL3369 and BPSL2287 whereas IgG2A but not IgG1 was produced in response to proteins BPSL1897 and BPSL2765. The inclusion of

Table 5

IgG1 and IgG2a antibody responses to chronic stage vaccine antigens.

\begin{tabular}{|c|c|c|c|}
\hline \multirow[t]{2}{*}{ Protein } & \multirow[t]{2}{*}{ Antibody subclass } & \multicolumn{2}{|c|}{ ELISA titre after immunisation with } \\
\hline & & Mixed chronic stage antigens & Adjuvant \\
\hline BPSL1897 & $\operatorname{IgG1}$ & 25 & $<25$ \\
\hline BPSL1897 & $\operatorname{IgG} 2 \mathrm{a}$ & 300 & $<25$ \\
\hline BPSL3369 & IgG1 & 307,200 & $<25$ \\
\hline BPSL3369 & $\operatorname{IgG} 2 a$ & 819,200 & $<25$ \\
\hline BPSL2765 & $\operatorname{IgG1}$ & 3225 & $<25$ \\
\hline BPSL2765 & $\operatorname{IgG} 2 \mathrm{a}$ & 500 & $<25$ \\
\hline BPSL2287 & $\operatorname{IgG1}$ & 307,200 & $<25$ \\
\hline BPSL2287 & $\operatorname{IgG} 2 \mathrm{a}$ & 102,400 & $<25$ \\
\hline
\end{tabular}

Groups of 10 mice were immunised with $5 \mu$ g each of chronic stage vaccine antigens (BPSL2765, BPSL3369, BPSL2287, BPSL1897). Some groups were dosed with CPS or LolC alone or in combination with proteins. Immunogens were formulated in SAS adjuvant. Mice were given 3 doses at 14 day intervals with titres measured 14 days after the final immunising dose. The lower limit of detection was 25 .

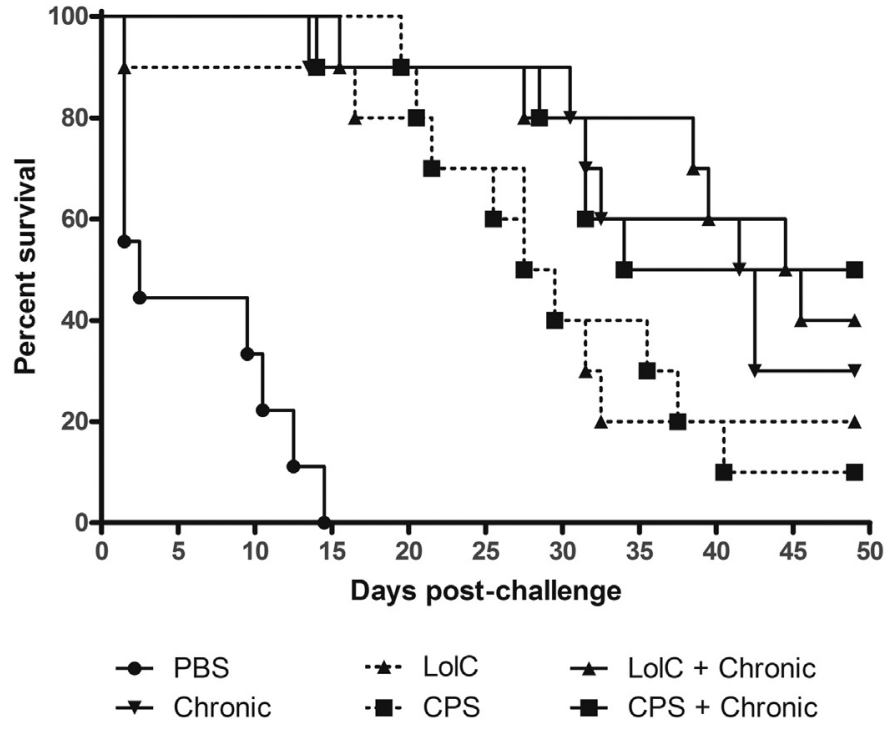

Fig. 2. Survival of mice ( $n=10$ per immunogen) which had been immunised on days 0,14 and 28 and challenged with $7.46 \times 10^{4}$ CFU of B. pseudomallei K96243 $\left(100 \times \mathrm{LD}_{50}\right)$ via the i.p. route.

CPS or LolC in the formulation of chronic stage antigens did not modify the antibody responses to these chronic stage proteins (data not shown)

\subsection{Protection studies}

To determine whether B. pseudomallei BPSL2765, BPSL3369, BPSL2287 and BPSL1897 are protective antigens, groups of BALB/C mice were immunised as described above and challenged a month later with $7.46 \times 10^{4} \mathrm{CFU}$ of $B$. pseudomallei $\mathrm{K} 96243$ via the intraperitoneal route. Other groups of mice were immunised with either CPS or LolC, or a combination of chronic antigens and CPS or LolC, since CPS and LolC are the most protective vaccine candidates identified to date [32]. The challenged mice were observed until 49 days post infection (Fig. 2).

The mean time to death (mttd) of the group of control mice dosed with PBS was 2.5 days. All of the immunised mice showed significant protection $(p<0.01)$ compared to these control mice. The immunised mice showed similar levels of protection until day 21 , but after that time groups immunised with preparations containing chronic stage antigens showed greater protection than the groups immunised with either CPS or LolC $(p<0.01)$. The mttd of mice dosed with LolC or CPS was 28.5 days and the mttd of mice dosed with chronic stage antigens was 42 days. The mttd of groups of mice immunised with a combination of LolC or CPS and the chronic stage antigens was 45 and 41.5 days, respectively, and there was no significant increase in protection of these mice compared to mice immunised with chronic stage antigens alone.

\section{Discussion}

A wide range of melioidosis vaccine candidates have been tested in mice over the past decade. None of these candidates consistently provide sterile immunity against disease, but some extend the time to death of mice challenged with B. pseudomallei. It is uncertain whether it will be possible to develop vaccines that provide robust and sterile immunity, and we report here the potential for chronic stage vaccine antigens to contribute to protection.

Recently, tuberculosis vaccines that combine virulence factors expressed during the early stages of disease with latencyassociated antigens have been shown to provide enhanced 
protection against disease, and to control re-activation [14,15]. These vaccines (ID93 and H56) are currently being trialled in humans [17]. Chronic disease is an important feature of melioidosis, but the mechanisms that underlie persistence and the immune responses that develop during chronic infection are poorly characterised. Multinucleated giant cells and granulomas are histological features of both chronic melioidosis and chronic tuberculosis in humans and experimental animals suggesting that, as in tuberculosis, intracellular survival is key to the persistent and chronic phase of melioidosis. Devising vaccines against pathogens that can enter a latent, subclinical state capable of causing chronic or recurrent disease is a major challenge.

Two partially protective sub-unit antigens that we have identified to date are LolC [33] and CPS [32]. Immunisation with $B$. pseudomallei CPS extends the time to death but does not provide sterile immunity, instead the acute disease is shifted to the chronic form. Immunity directed against CPS is expected to be due to the presence of antibodies. This is consistent with the protective capacity of CPS specific monoclonal and polyclonal antibodies when administered passively to animals [32]. A similar pattern of protection is seen after immunisation with LolC, a protein component of a lipoprotein transport system. The immunisation of mice results in the appearance of a more chronic form of disease following challenge [33]. Therefore, to go beyond the level of protection afforded by CPS or LolC alone, different vaccine components may be required.

In this study we aimed to improve on the protection elicited by immunisation with CPS or LolC alone through identification of antigens that are upregulated during chronic or recurrent melioidosis. We have identified a subset of $B$. pseudomallei genes that are expressed during chronic melioidosis in mice. The level of expression of these genes was measured relative to two housekeeping genes (aceA and gltB), in RNA isolated from spleen or lung tissues taken from chronically infected mice. We selected these housekeeping genes because we had previously shown that they were not differentially regulated in bacteria taken from acutely infected mice, compared to bacteria grown in broth cultures [18]. Using RNA isolated from chronically infected spleens, the relative levels of expression of the chronic stage antigen genes were similar when compared to the level of expression either ace $A$ or gltB. However, in lung tissues the ratio compared to aceA was approximately 10 -fold higher than the ratio compared to gltB (Table 3). This finding suggests that aceA or gltB are differentially expressed in different tissues of chronically infected mice.

BPSL1897 is a hypothetical protein located in the cytoplasmic membrane and contains a Tad-E domain that is often found in pilus assembly protein components. BPSL3369 encodes an acetaldehyde dehydrogenase and has a cytoplasmic cellular location. BPSL0296 is a small, hypothetical protein of unknown cellular location. BPSL3247 encodes a putative lipoprotein and has multiple predicted cell localisations. BPSL2287 is an iron cluster assembly protein and BPSL1899 encodes a putative fimbrial assembly like protein. Putative chronic stage vaccine candidates BPSL2765, BPSL3369, BPSL2287 and BPSL1897 were selected for protection studies in mice. In addition, BPSL2765, an outer membrane protein (OmpA), was included in the vaccine antigen pool as previous studies have shown that the antibody response to this protein is correlated with reduced incidence of recurrent disease in humans [30].

Mice immunised with the pool of chronic stage antigens developed antibody responses to all of the proteins. The response to BPSL1897 and BPSL2765 demonstrated a bias towards a Th1 type response, evidenced by high levels of IgG2a whilst the response to BPSL3369 and BPSL2287 indicated both Th1 and Th2 type responses, evidenced by elevated levels of both $\operatorname{IgG} 2 \mathrm{a}$ and $\operatorname{IgG} 1$.
Immunisation with the combination of chronic stage antigens provided protection against experimental melioidosis. Our results indicate that by including chronic stage antigens protection is enhanced compared to two of the leading sub-unit candidates (CPS and LolC) identified to date. Further work should determine whether one or more of the proteins are responsible for the enhanced protection we have seen. However, even with the combinations of antigens we tested we were unable to demonstrate sterile immunity against the challenge dose we tested. Therefore, it is clear that the antigens we have identified, even in combination, are not sufficient to provide an effective sub-unit vaccine. Against this background, it would be valuable to identify and test additional chronic stage proteins as protective antigens.

\section{Authors contributions}

This study was conceived by OLC, MB and RWT. LC, CH and GB carried our chronic infection studies and prepared tissues for mRNA isolation and isolated mRNA. OLC carried out the bioinformatics analysis and the analysis of gene expression. LJG, PL and LP cloned, overexpressed and purified the proteins used in this study under the guidance of MB. AS carried out the mouse protection studies under the guidance of JP. OLC, LJG, GB and RWT wrote the manuscript.

\section{Conflict of interest statement}

The authors have no competing interests.

\section{Acknowledgements}

This work was supported by Fondazione CARIPLO (contract number 2009-3577) “From Genome to Antigen: a Multidisciplinary Approach towards the Development of an Effective Vaccine against Burkholderia pseudomallei, the Etiological Agent of Melioidosis."

\section{References}

[1] Cheng AC, Currie BJ. Melioidosis: epidemiology, pathophysiology and management. Clin Microbiol Rev 2005;18:383-416.

[2] Limmathurotsakul D, Wongratanacheewin S, Teerawattanasook N, Wongsuvan G, Chaisuksant S, Chetchotisakd P, et al. Increasing incidence of human melioidosis in Northeast Thailand. Am J Trop Med Hyg 2010;82:1113-7.

[3] Currie BJ, Fisher DA, Howard DM, Burrow JN, Selvanayagam S, Snelling PL, et al. The epidemiology of melioidosis in Australia and Papua New Guinea. Acta Trop 2000;74:121-7.

[4] Wiersinga WJ, van der Poll T, White NJ, Day NP, Peacock SJ. Melioidosis: insights into the pathogenicity of Burkholderia pseudomallei. Nat Rev Microbiol 2006:4:272-82

[5] Dance DAB, Wuthiekanun V, Chaowagul W, White NJ. The antimicrobial susceptibility of Pseudomonas pseudomallei-emergence of resistance in vitro and during treatment. J Antimicrob Chemother 1989;24:295-309.

[6] White NJ. Melioidosis. Lancet 2003:361:1715-22

[7] Dance D. Treatment and prophylaxis of melioidosis. Int J Antimicrob Agents 2014;43:310-8

[8] Wiersinga WJ, Currie BJ, Peacock SJ. Melioidosis. N Engl J Med 2012;367:1035-44.

[9] Limmathurotsakul D, Peacock SJ. Melioidosis: a clinical overview. Br Med Bull 2011;99:125-39.

[10] Peacock SJ, Limmathurotsakul D, Lubell Y, Koh GC, White LJ, Day NP, et al. Melioidosis vaccines: a systematic review and appraisal of the potential to exploit biodefense vaccines for public health purposes. PLoS Negl Trop Dis 2012;6:e1488

[11] Patel N, Conejero L, De Reynal M, Easton A, Bancroft GJ, Titball RW. Development of vaccines against Burkholderia pseudomallei. Front Microbiol 2011;2:198.

[12] Silva EB, Dow SW. Development of Burkholderia mallei and pseudomallei vaccines. Front Cell Infect Microbiol 2013:3:10.

[13] Choh LC, Ong GH, Vellasamy KM, Kalaiselvam K, Kang WT, Al-Maleki AR, et al. Burkholderia vaccines: are we moving forward? Front Cell Infect Microbiol 2013:3:5.

[14] Aagaard C, Hoang T, Dietrich J, Cardona PJ, Izzo A, Dolganov G, et al. A multistage tuberculosis vaccine that confers efficient protection before and after exposure. Nat Med 2011;17:189-94 
[15] Bertholet S, Ireton GC, Ordway DJ, Windish HP, Pine SO, Kahn M, et al. A defined tuberculosis vaccine candidate boosts BCG and protects against multidrugresistant Mycobacterium tuberculosis. Sci Transl Med 2010;2:53ra74.

[16] Lin PL, Dietrich J, Tan E, Abalos RM, Burgos J, Bigbee C, et al. The multistage vaccine $\mathrm{H} 56$ boosts the effects of BCG to protect cynomolgus macaques against active tuberculosis and reactivation of latent Mycobacterium tuberculosis infection. J Clin Invest 2012;122:303-14.

[17] Montagnani C, Chiappini E, Galli L, de Martino M. Vaccine against tuberculosis: what's new? BMC Infect Dis 2014;14(Suppl. 1):S2.

[18] Ooi WF, Ong C, Nandi T, Kreisberg JF, Chua HH, Sun G, et al. The conditiondependent transcriptional landscape of Burkholderia pseudomallei. PLoS Genet 2013;9:e1003795

[19] Titball RW, Russell P, Cuccui J, Easton A, Haque A, Atkins T, et al. Burkholderia pseudomallei: animal models of infection. Trans $\mathrm{R}$ Soc Trop Med Hyg 2008;102(Suppl. 1):S111-6.

[20] Yu NY, Wagner JR, Laird MR, Melli G, Rey S, Lo R, et al. PSORTb 3.0: improved protein subcellular localization prediction with refined localization subcategories and predictive capabilities for all prokaryotes. Bioinformatics 2010;26:1608-15.

[21] Haque A, Easton A, Smith D, O'Garra A, Van Rooijen N, Lertmemongkolchai G, et al. Role of T cells in innate and adaptive immunity against murine Burkholderia pseudomallei infection. J Infect Dis 2006;193:370-9.

[22] Sim BM, Chantratita N, Ooi WF, Nandi T, Tewhey R, Wuthiekanun V, et al Genomic acquisition of a capsular polysaccharide virulence cluster by nonpathogenic Burkholderia isolates. Genome Biol 2010;11:R89.

[23] Alexeyev MF. The pKNOCK series of broad-host-range mobilizable suicide vectors for gene knockout and targeted DNA insertion into the chromosome of gram-negative bacteria. Biotechniques 1999;26:824-6, 828.

[24] Jones SM, Ellis JF, Russell P, Griffin KF, Oyston PC. Passive protection against Burkholderia pseudomallei infection in mice by monoclonal antibodies against capsular polysaccharide, lipopolysaccharide or proteins. J Med Microbiol 2002;51:1055-62.

[25] Atkins TP, Prior RG, Mack K, Russell P, Nelson M, Prior J, et al. Characterisation of an acapsular mutant of Burkholderia pseudomallei identified by signature tagged mutagenesis. J Med Microbiol 2002;51:539-47.

[26] Burtnick MN, Heiss C, Roberts RA, Schweizer HP, Azadi P, Brett PJ. Development of capsular polysaccharide-based glycoconjugates for immunization against melioidosis and glanders. Front Cell Infect Microbiol 2012;2:108.

[27] Scott AE, Ngugi SA, Laws TR, Corser D, Lonsdale CL, D’Elia RV, et al. Protection against experimental melioidosis following immunisation with a lipopolysaccharide-protein conjugate. J Immunol Res 2014;2014:392170.

[28] Conejero L, Patel N, de Reynal M, Oberdorf S, Prior J, Felgner PL, et al. Low-dose exposure of C57BL/6 mice to Burkholderia pseudomallei mimics chronic human melioidosis. Am J Pathol 2011;179:270-80.

[29] Cupp-Vickery JR, Silberg JJ, Ta DT, Vickery LE. Crystal structure of IscA an iron-sulfur cluster assembly protein from Escherichia coli. J Mol Biol 2004;338:127-37.

[30] Suwannasaen D, Mahawantung J, Chaowagul W, Limmathurotsakul D, Felgner PL, Davies H, et al. Human immune responses to Burkholderia pseudomallei characterized by protein microarray analysis. J Infect Dis 2011;203:1002-11.

[31] Gourlay LJ, Peri C, Ferrer-Navarro M, Conchillo-Sole O, Gori A, Rinchai D, et al. Exploiting the Burkholderia pseudomallei acute phase antigen BPSL2765 for structure-based epitope discovery/design in structural vaccinology. Chem Biol 2013;20:1147-56.

[32] Nelson M, Prior JL, Lever MS, Jones HE, Atkins TP, Titball RW. Evaluation of lipopolysaccharide and capsular polysaccharide as subunit vaccines against experimental melioidosis. J Med Microbiol 2004;53:1177-82.

[33] Harland DN, Chu K, Haque A, Nelson M, Walker NJ, Sarkar-Tyson M, et al. Identification of a LolC homologue in Burkholderia pseudomallei, a novel protective antigen for melioidosis. Infect Immun 2007;75:4173-80. 